\title{
Financial Management Throughout End-to-End Business Processes
}

At Huawei, business plays a leading role and accounting plays an oversight role. Finance is positioned to serve business and create value, with its oversight role integrated into processes. The goals for the first phase of the Integrated Financial Services (IFS) program are: accurately recognizing revenue, accelerating cash inflows, ensuring visibility of project profits and losses, and managing business risks. These goals are set to address weak links of the company's end-to-end business processes for value creation. It is a long-term task for Huawei to build and continuously improve its process-based organization and management systems for major business processes.

Opportunity to Cash (OTC) is a major business process that defines how Huawei does business with its customers. It carries the company's major flows of physical goods, money, and working capital. To ensure the process runs smoothly, Huawei must first improve contract quality at the very beginning to control contract risks. Second, the company must go back over the entire OTC process, with a focus on billing, to review and streamline all activities and work requirements as necessary. Third, to make the process run faster, the company must keep customer PO information transparent throughout the process and transform related business processes in an integrated manner.

Integrated Product Development (IPD) is a major process for marketoriented innovation. In this process, Finance manages product development as an investment. Finance needs to focus on how to monetize

(C) The Author(s) 2019

W. Huang, Built on Value, https://doi.org/10.1007/978-981-13-7507-1_8 
opportunities and plays an active role in IPD's cross-departmental decision making, decision checkpoint (DCP) reviews, and product portfolio management. Finance can make the product development process visible and support the commercial success of product development through planning, budgeting, and accounting.

Benchmarked against IBM's procurement process, Huawei's Procureto-Pay (PTP) process includes a clear matrix of separation of duties (SOD) and assessment mechanisms. To ensure payment security, key control points (KCPs) are set at all stages of the process, including invoice receiving and processing, invoice matching, duplicate payment checking, and payment. To ensure project operations responsibilities are properly fulfilled, the company takes a methodical approach to project-driven procurement and stretches procurement cost accounting down to the project level. This way, procurement processes are integrated with financial processes.

Clouds, rainwater, and channels are how Huawei describes its approach to management transformation. Huawei's management philosophy is like a cloud; rainwater is Huawei's business activities; and channels are processes and rules established through systematic transformation after Huawei's operations were benchmarked against the best practices of Western companies. Clouds are valuable only when they turn into rainwater. And the rainwater needs to be channeled properly in order to generate electricity. Without the right channels to guide the rainwater, it will flow anywhere, and its energy will dissipate.

This chapter describes how financial management is integrated into Huawei's three major end-to-end business processes and how Finance provides effective oversight while serving business.

\subsection{Financial Management Throughout the OTC Process}

\subsubsection{KCPs Throughout the OTC Process}

Building a process-based organization and management system that suits the OTC process is a long-term task for Huawei

Bidding, contract signing, delivery, billing, and payment collection are the key stages of one of our company's major business processes. They largely determine the flow of our physical goods and cash. One of our long-term tasks is to build a process-based organization and management 
system tailored to this major business process. Growing from a small company, we've always operated less efficiently than our Western peers. We have serious overlapping, disconnection, duplication, low efficiency, and segmented processes in operations and delivery. We lag far behind our peers when it comes to Days Sales Outstanding (DSO) and Inventory Turnover (ITO). There is still much we can do to improve inventory and cash turnover, and reduce end-to-end costs. This is a key battlefield on which we should implement our "Dig In and Widen Out" strategy. IPD, another major business process, is another area where we can build cost advantages into product design. (Ren Zhengfei: Digging In, Widening Out-Speech at the Commendation Meeting of the Operations and Delivery Division, Huawei Executive Office Speech No. [2009] 009)

\section{Net cash inflow is the lifeline of our company}

Without water and food, you would burn to death in a desert. Whether or not our company can maintain steady growth depends on whether we have enough food. Winter is coming. We must prepare enough clothing. What exactly is our company's clothing though? Internally, it is cash flow; externally, it is market size and market space. (Ren Zhengfei: Corporate Development Should Focus on Meeting the Current Needs of CustomersSpeech at a Meeting with Key Employees of the Optical Network Product Line on April 18, 2002)

Maintaining sufficient cash flow is the only way for us to survive. Our biggest risk is cash flow, not anything else. (Ren Zhengfei: Strengthening Payment Collection and Improving Cash Flow-Speech at the EMT ST Meeting on February 28, 2006, Huawei Executive Office Speech No. [2006] 007)

Net cash inflow is the lifeline of our company. We must place more emphasis on net cash flow during performance appraisals. And now we must assign a proper weight to net cash flow during representative office performance appraisals. During this process, we must avoid being too radical as this may make us unable to incentivize or push the offices to maintain a proper net cash flow. (Source: Minutes of the Report on the Performance Appraisal and Incentivization Plan for Frontline BUs, EMT Meeting Minutes No. [2009] 006)

We can conduct more business in countries with strict foreign exchange controls if we can repatriate more money. We need to adopt a pragmatic approach in these countries. What are real customer needs? Those are the needs of customers that can pay. In these countries, payment collection is our biggest difficulty. If we can collect payments, we won't worry about 
sales; we may even raise prices. (Ren Zhengfei: Minutes of the Work Report by the Algeria Representative Office, Huawei Executive Office Speech No. [2014] 070)

In countries with strict foreign exchange controls, we should base our investment on how much money we can collect. We decide to take contracts based on how much money we can repatriate back to China. The value of a contract can be $10 \%$ or $20 \%$ higher than the amount that can be repatriated. Our only way to weather the current financial crisis is to boost efficiency and profitability as much as we can. If we can do that, then the financial crisis will not affect us. The crisis is not over and will last a long time. (Ren Zhengfei: Comments to Staff of the Brazil Representative Office and Brazil Supply Center, Huawei Executive Office Speech No. [2014] 050)

Accurately recognizing revenue based on contract terms and project delivery status

Since 2009, we have recognized revenue upon receipt of preliminary acceptance certificates (PACs). This way we can appropriately match revenue recognition with cash inflows. However, we should not simply recognize revenue upon the receipt of a single document. We must also look at project delivery status to match revenue recognition with actual business progress. Project financial controllers (PFCs) must assume this responsibility. (Ren Zhengfei: Keeping Customer PO Information Transparent to Support Payment Collection, Revenue Recognition, and Project Budgeting and Accounting-Speech at a Work Report by the IFS Project Team on December 29, Huawei Executive Office Speech No. [2009] 002)

We cannot take a one-size-fits-all approach to revenue recognition. Business departments are the owners of revenue recognition. They must promptly provide Finance with the key information that supports revenue recognition. Finance then needs to carefully check the information and determine an appropriate method and timing for revenue recognition based on contract terms. (Ren Zhengfei: Keeping Customer PO Information Transparent to Support Payment Collection, Revenue Recognition, and Project Budgeting and Accounting-Speech at a Work Report by the IFS Project Team on December 29, Huawei Executive Office Speech No. [2009] 002)

Setting up a joint liability system for billing; the purpose of delivery is to collect payments

We must create a solid "Iron Triangle" team for billing and payment collection. In this team, the sales financing and payment collection man- 
ager must collaborate closely with both the front-end contract manager and the back-end delivery manager. This creates a robust triangle. We must also develop a joint liability system for billing, under which the three managers will be jointly responsible. In fact, these three roles constitute a billing team. (Ren Zhengfei: Keeping Customer PO Information Transparent to Support Payment Collection, Revenue Recognition, and Project Budgeting and Accounting-Speech at a Work Report by the IFS Project Team on December 29, Huawei Executive Office Speech No. [2009] 002)

We must deliver projects and collect payments according to visible progress, or delivery milestones. For example, we can collect partial payment after we finish laying the foundation of a house, even though we have not finished building the entire house. (Ren Zhengfei: Keeping Customer PO Information Transparent to Support Payment Collection, Revenue Recognition, and Project Budgeting and Accounting-Speech at a Work Report by the IFS Project Team on December 29, Huawei Executive Office Speech No. [2009] 002)

We must build a mechanism for regular customer communication to ensure payments are collected based on delivery milestones and to make billing more accurate and effective. The Accounting Management Department is responsible for exercising internal controls over invoices. (Ren Zhengfei: Keeping Customer PO Information Transparent to Support Payment Collection, Revenue Recognition, and Project Budgeting and Accounting-Speech at a Work Report by the IFS Project Team on December 29, Huawei Executive Office Speech No. [2009] 002)

We must systematically manage billed and unbilled accounts receivable (AR). We must also establish a responsibility matrix for handling AR disputes and clearly identify who is responsible for dispute management. These individuals are usually representative office deputy general managers or regional vice presidents in charge of sales. (Ren Zhengfei: Keeping Customer PO Information Transparent to Support Payment Collection, Revenue Recognition, and Project Budgeting and Accounting - Speech at a Work Report by the IFS Project Team on December 29, Huawei Executive Office Speech No. [2009] 002)

The purpose of managing credit is to drive healthy, sustainable growth in sales and allocate resources to more valuable projects. The job of the credit management team is to disclose risks. Sales teams make decisions on these risks within the scope of their authority. (Ren Zhengfei: Keeping Customer PO Information Transparent to Support Payment Collection, 
Revenue Recognition, and Project Budgeting and Accounting-Speech at a Work Report by the IFS Project Team on December 29, Huawei Executive Office Speech No. [2009] 002)

The sales department must provide complete and correct contract information to downstream departments

We only have two stages: securing a contract and fulfilling a contract. What matters during these two stages are implementation costs and final profits. The core terms of a contract like delivery and payment are very important. The sales department must provide complete and correct contract information to downstream departments. (Ren Zhengfei: Keeping Customer PO Information Transparent to Support Payment Collection, Revenue Recognition, and Project Budgeting and Accounting-Speech at a Work Report by the IFS Project Team on December 29, Huawei Executive Office Speech No. [2009] 002)

Making changes to a contract is inevitable during sales. The key to contract changes is not the changes themselves. What actually matters is ensuring that the contract management and delivery teams are accurately informed of the changes. (Ren Zhengfei: Keeping Customer PO Information Transparent to Support Payment Collection, Revenue Recognition, and Project Budgeting and Accounting-Speech at a Work Report by the IFS Project Team on December 29, Huawei Executive Office Speech No. [2009] 002)

\section{Better managing the end-to-end delivery process}

We must gradually integrate project delivery plans with manufacturing and shipment plans. We must manage shipment, delivery, acceptance, and payment collection on a site-by-site basis. Site-based shipment and management is an important way to increase the efficiency of working capital and achieve rapid and low-cost delivery. (Source: Resolution on Enhancing Working Capital Management and Achieving Site-based Shipment by Managers at All Levels, EMT Resolution No. [2007] 040)

We must better manage the end-to-end delivery process. During current contract execution, functional departments are only responsible for specific segments of the process from bidding to payment collection. An individual or a team must be designated to monitor and coordinate the entire process and be accountable for its final results. The IPD management system already ensures that the IPD process flows smoothly from end to end. The next step is to establish a department responsible for delivery from end to end and to develop an operational mechanism. We must shorten days in inventory and the acceptance cycle by improving 
contract quality, project delivery, and acceptance, and providing timely and whole-set shipments to sites. It's important to remain realistic when we set improvement targets. Our targets must be objective and measurable. (Source: Guidelines for Delivery, Working Capital Management, and Team Building, EMT Meeting Minutes No. [2008] 013)

We must streamline cost management from end to end and avoid fragmented cost management. By relying on its cost committee, each product line needs to coordinate the cost management efforts of all relevant functions like manufacturing, logistics, project delivery, maintenance, R\&D, and technical sales. All the costs must be reflected in product package requirements. This way, we can build our cost competitiveness into the design and R\&D stages of our process. We don't want to play whack-amole or do meaningless work. (Source: Minutes of the Report on the 2009 HI Performance Review, EMT Meeting Minutes No. [2009] 038)

We must take an end-to-end approach to the transformation of our supply chain, which means we should aim to be the best in every link of our chain. First, we need to make our R\&D the best in the world. This does not just mean that our R\&D personnel feel that we are the best. Our customers must also feel the same way. Second, we need to make our manufacturing the best in the world. Since we are an industry leader in $\mathrm{R} \& \mathrm{D}$, our manufacturing must also be industry-leading. Third, we must make sure our shipments are done right. We must have correct contracts and deliver on the contracts, covering all supply chain and contract acquisition activities. Fourth, we must provide the best services. Since we earn money from customers, we need to serve them well, no matter how difficult it is. Customers are always there and we need to make them happy. Otherwise, we will not be able to survive. (Ren Zhengfei: Doing It Right the First Time-Speech at the Global Warehouse Meeting, Huawei Executive Office Speech No. [2014] 060)

\subsubsection{Controlling Contract Quality at the Very Beginning}

We need to improve our contract quality and reduce contract risks and gradually move from massive, low-margin growth to more profitable growth. We will gradually strengthen the assessment and control of contract risks to gradually improve contract quality. We must focus on target carriers and further standardize business activities such as financing and payment collection. (Ren Zhengfei: Speech at a Meeting with Members of the Financing Team, 2005) 
We will gradually strengthen the assessment and control of contract risks to gradually improve contract quality. The Treasury Management Department must get closer to financial resources and the Market Finance Department must get closer to customers. No matter how tough a project is, the Market Finance Department must learn how to understand customer needs, provide guidance for financing, avoid major risks, and facilitate project success. Since the Market Finance Department takes different approaches in different circumstances, their job is difficult and they must be good strategists when on the front line. (Ren Zhengfei: Speech at a Meeting with Members of the Financing Team, 2005)

A good contract lays the foundation for high-quality delivery and profitability. We must stick to our principles during contract negotiations, fight for favorable contract terms, and avoid making unprincipled concessions. (Source: Guidelines for Delivery, Working Capital Management, and Team Building, EMT Meeting Minutes No. [2008] 013)

We don't encourage last-minute rushes to get sales orders, because that sacrifices contract quality and compromises the company's future development. Financial analysis must provide both positive and negative feedback on the company's operations management to truly reflect performance. Finance must have checks and balances in place to control last-minute rushes. It must also continue to step up efforts to audit business data, ensuring that financial data correctly mirrors company performance. (Source: Minutes of the Report on the 2011 HI Performance Review, EMT Meeting Minutes No. [2011] 011)

Regional and representative office CFOs are responsible for overseeing the quality of contracts in regions within their purview. They must dare to veto poor-quality contracts. This can help establish checks and balances between regional CEOs and CFOs. CFOs at all levels must participate in pre-sales contract reviews and must have the courage to veto poor-quality contracts. Contracts vetoed by CFOs must be escalated to a higher-level contract review team. The contract review team of the same level will no longer have the decision-making authority over the vetoed contracts. CFOs that can't handle this work must be replaced promptly. (Source: Minutes of the Report on the 2011 HI Performance Review, EMT Meeting Minutes No. [2011] 011)

Transaction quality is not the same as contract quality. Contract quality is not the same as contract terms. Our ultimate goal is to improve transaction quality and achieve our expected operating results, rather than to simply improve the quality of contract terms. We must not forget that 
we are building a church when moving bricks. A good contract is made in the initial phases of project operations, and is not the result of contract review. To improve contract quality, we need to do more in initial project phases and in building customer relationships. We can't just focus on contract terms. More importantly, we can't simply compromise our profits or overpromise during contract negotiations. (Source: Minutes of the Report on Improving Contract Quality, EMT Meeting Minutes No. [2011] 012)

We are overly random in our contract terms, which creates huge risk. At the moment, a contract takes effect as soon as it is signed by a frontline manager. We must change this practice. We need to build a centralized transaction management center and a mechanism for contract approval. A contract must be signed by those with the authority to do so. Not everyone has the authority to sign a contract. All contractual documents need to be signed by authorized staff. Contractual documents include but are not limited to bids, quotations, clarification letters, contracts, appendixes, PowerPoint presentations, and emails that could be viewed as elements of a contract by local law. (Ren Zhengfei: Speech at the EMT ST Meeting, August 31, 2012)

We must establish approaches, management systems, and associated performance appraisal systems to improve contract quality from end to end. Improvements in contract quality must be given full consideration in performance appraisals and incentive mechanisms. Performance appraisals must be closely linked to sales revenue, profits, and cash flow. Incentive mechanisms should give higher bonuses to operating units that have better contract quality, and those with poor contract quality must bear the losses. (Ren Zhengfei: Guidelines on the Analysis of the Business Environment and Key Business Strategies, Corp. Doc. No. [2012] 081)

Customers need advanced, high-quality, and cost-effective products, along with good services. We want market success and profits. In addition, we need to address the conflict between increasing compensation requirements of our excellent employees and the company's necessity of investing more in cutting-edge technologies. Therefore, when we negotiate on prices and commercial contract terms, it doesn't mean we are not humble. (Ren Zhengfei: Being a Humble Leader-Speech at the 2014 Huawei Market Conference, Huawei Executive Office Speech No. [2014] 014)

When we say "from end to end", both ends are customer needs. For Huawei, starting and ending with customer needs is currently unrealistic and difficult. So we must make this process shorter: from the company to representative offices and from representative offices to sites. We must 
start with signing high-quality contracts and accurately understanding customer needs. We must better understand customer needs and improve our execution skills to ensure that everything at the source is accurate. We have come this far, but just think about how much money we have wasted along the way. We have launched the Five Ones and CIAG projects, but no matter how important they are, ensuring the accuracy of customer needs - the source of everything we do - is still the most important. We are still unclear about many contract scenarios, so we need to gradually standardize them as this will help increase efficiency. This is the first point I want to make. The second point is that we must have accurate contract estimation. These are our two weaknesses in customer engagement. Right now, our delivery is only confined to project delivery, but this does not mean this is our sole goal. We must also accurately understand customer needs and improve contract quality as this is the source of everything we do. (Ren Zhengfei: Speech at a Meeting with Employees of the Peru Representative Office, Huawei Executive Office Speech No. [2014] 040)

We used to focus on sales. Now, we have shifted our focus to developing representative offices in an all-round manner. Representative office profit growth must be built on high-quality contracts. Our contracts must undergo two approvals. First, configuration and price clauses must be approved, and second, contractual commitments must be approved. The Regions Management Department needs to develop a guide for this, stipulating which clauses cannot be skipped during the collective review of contracts. What caused the Central Bank of Bahrain to collapse? It was the bank's unclear authorization system. During the second collective contract review, you first need to check whether all products to be sold are on the approved list of sellable products. You must not make a commitment on products not on the list. Second, you must review and check items like whether there are clauses stipulating the beginning and ending years of a contract, whether fees and interests are claimed for delayed payments, and whether legal compliance is ensured. (Ren Zhengfei: There Will Not Always Be Flowers Along the Road Abead-Speech at the HI Huawei Market Conference, Huawei Executive Office Speech No. [2016] 079)

Sales people need to thoroughly analyze and understand many scenarios. There is a wide range of expertise that sales people can study. Where should they start? The company emphasizes two things. One is contract quality improvement. Managers cannot improve contract quality by being overconfident or making rash decisions. Contract quality involves a lot of scenario design. Contract scenario experts play a very important role in 
this process. The other thing is scenario-targeted improvement during contract execution. Contract scenario experts can play a role in improving both contract quality and delivery quality. I hope that our contract scenario experts will be able to take up these meaningful responsibilities in sales. You can envision future trends with the big picture in mind. You have to shoulder greater responsibility to grow, to play a truly meaningful role, and to advance your position in the company. The role of contract scenario expert is something new. You can discuss and decide what responsibilities this role should assume. You need to know what the top priorities are in the eyes of regional presidents. You should think about how you can become a Liu Yalou, ${ }^{1}$ and the chief-of-staff to your commander! (Ren Zhengfei: Speech at a Meeting with Contract Scenario Experts, Huawei Executive Office Speech No. [2017] 020)

\subsubsection{Integrating Payment Collection, Revenue Recognition, and Project Budgeting and Accounting Based on Customer Contracts/POs}

Reviewing and streamlining activities and work requirements, with a focus on billing

Billing means we issue a customer-accepted invoice based on a contract. As long as we complete billing, it means the customer has formally accepted the project delivered by Huawei, and is obligated to make payment. It also means that all barriers of payment collection on the Huawei side have been removed. Therefore, we must look back over the OTC process, with a focus on billing, and review and streamline activities and work requirements as necessary. In other words, we must coordinate all our efforts based on billing requirements and analyze how we should sign contracts and deliver projects by looking back over the process. (Source: Resolution on Process Optimization at Representative Offices, EMT Resolution No. [2009] 003)

Delivery project managers must develop delivery plans based on the delivery units and billing schedules stipulated in contracts, deliver projects as stipulated, and promptly trigger billing. Effectively triggering billing is an important responsibility for delivery project managers and as such is

\footnotetext{
${ }^{1}$ General Liu Yalou (April 1910-May 1965) was the first commander-in-chief of the People's Liberation Army Air Force, known for his victories in Manchuria during the Chinese Civil War.
} 
one of their KPIs. Only when a project is successfully delivered and a customer-accepted invoice is issued can we say that delivery project managers have effectively fulfilled their responsibilities. Delivery project managers are responsible for the effectiveness and authenticity of billing, or customer-accepted invoices. They must properly manage their projects' contracts and POs, and completely and accurately record any configuration information or changes about sites delivered. The contract managers of the Contract Support Office (CSO) are responsible for triggering and managing billing. Business personnel must ensure business authenticity while financial personnel must faithfully keep accounts and play an auditing role. (Source: Resolution on Process Optimization at Representative Offices, EMT Resolution No. [2009] 003)

Keeping PO information transparent throughout the OTC process

Customers are placing a greater number of small POs under framework contracts. This trend will continue. As customer needs become increasingly diverse, customization will become a trend in the industry. Our competitiveness will then rely more on management than on technology. The biggest issue we have in keeping customer PO information transparent throughout the OTC process lies in the inconsistencies between our POs and customers'. As a result, customer PO information is missing during fulfillment within Huawei. Additionally, our IT systems cannot process POs in an automated and integrated manner. We need to integrate both data flows and business flows. An IT system has no value unless it actually helps with business operations. (Ren Zhengfei: Keeping Customer PO Information Transparent to Support Payment Collection, Revenue Recognition, and Project Budgeting and Accounting-Speech at a Work Report by the IFS Project Team on December 29, Huawei Executive Office Speech No. [2009] 002)

PO bundling is forbidden because it makes it harder for downstream departments to understand the PO and increases fulfillment costs. We must forbid PO bundling and encourage large framework contracts under which small POs can be placed. The company must make it very clear that POs cannot be bundled and contracts must be separately signed for different types of business. Supply chain and GTS departments must manage their work by customer PO. (Ren Zhengfei: Keeping Customer PO Information Transparent to Support Payment Collection, Revenue Recognition, and Project Budgeting and Accounting-Speech at a Work Report by the IFS Project Team on December 29, Huawei Executive Office Speech No. [2009] 002) 
To address pain points relating to the OTC process, the IFS project team has developed a solution for integrating payment collection, revenue recognition, and project budgeting and accounting based on customer contracts and POs. This solution addresses problems that have plagued the company for years, effectively integrating transaction processes with financial processes, clarifying operational requirements, and improving data quality. Over the past few years, the company has seen an increase in its operating efficiency. This would have been impossible without the efficient collaboration between different departments. (Meng Wanzhou: Growing amid Transformation-Thoughts at the Closing of the IFS Program, Improvement Issue No. 463, 2014)

We must stay focused on our core business and integrate processes based on contract information flows. Contract information includes information about contract generation, project delivery, and payment collection. We can put other information aside for the time being. I previously said at a Lead to Cash (LTC) meeting that we aim to integrate contract information flows, and can put other modules aside, including optimization and capability modules. The GTS process has been basically integrated, and Yan $\mathrm{Lida}^{2}$ has managed to basically integrate the Enterprise BG's processes. The remaining systems that cannot be integrated are those we have been using for many years. Why have they become so entangled? Because we haven't focused on our core business and have incorporated all messes into these systems. Our processes must support the major systems of our core business. We need to promote more people working on these systems, so outstanding talent will be drawn to integrate these systems. After we integrate our major processes, we can continue to dig small ditches or channels. How could $\mathrm{Yu}$ the Great ${ }^{3}$ prevent disaster just by digging small ditches and not dredging big rivers? Why does our Quality, Business Process \& IT Management Department face such great difficulties? Because processes for our core business haven't been integrated. As a result, many resources have been wasted in developing hundreds of useless IT systems. (Ren Zhengfei: Speech at a Meeting with Employees of the Quality, Business Process \& IT Management Department, Huawei Executive Office Speech No. [2016] 094)

\footnotetext{
${ }^{2}$ Yan Lida currently serves as President of the Enterprise Business Group of Huawei.

${ }^{3} \mathrm{Yu}$ the Great (c. $2200-2100$ BC) was a legendary ruler in ancient China famed for his introduction of flood control.
} 
Keeping contract configuration information transparent is key to improving the operating efficiency of major business processes

Increasing PO processing efficiency, keeping contract configuration information transparent, and calculating billing amounts are the three hurdles field offices must overcome to increase operating efficiency in major business processes. At their core, these three issues all need transparent contract configuration information. We need to consider converting our customer bill of materials (CBOM) into a customized sales bill of materials (SBOM), which is easy to be converted into a build bill of materials (BBOM). This may increase HQ's maintenance workload but it can reduce the number of manual conversions needed to go between CBOMs, SBOMs, and BBOMs during the seven stages of our process and thus will benefit field offices. (Ren Zhengfei: Keeping Customer PO Information Transparent to Support Payment Collection, Revenue Recognition, and Project Budgeting and Accounting-Speech at a Work Report by the IFS Project Team on December 29, Huawei Executive Office Speech No. [2009] 002)

Product departments need to address the problem with integrated product configuration. They must work together with the Quality, Business Process \& IT Management Department to solve this problem and deliver a report to company management as soon as possible. This problem has limited our ability to grow our business and seize the strategic high ground. With regard to interconnecting PO information in our and customers' IT systems, we can begin with tier-1 carriers first. (Ren Zhengfei: Keeping Customer PO Information Transparent to Support Payment Collection, Revenue Recognition, and Project Budgeting and Accounting - Speech at a Work Report by the IFS Project Team on December 29, Huawei Executive Office Speech No. [2009] 002)

Payment collection is not the sole responsibility of Finance; all departments involved share this responsibility

Payment collection is the last activity of sales and is the most difficult. Quality of contractual payment terms, equipment delivery, installation, and acceptance all have a direct impact on payment collection. Therefore, payment collection is not the sole responsibility of the Market Finance Department; all departments involved need to share the responsibility. (Ren Zhengfei: Speech at the Annual Meeting of the Market Finance Department, 2005) 
We must work out a better approach to collecting overdue receivables. We cannot take a radical approach; otherwise, we may kill our golden goose. We must not press for payment at the expense of long-term interests. If payment collection problems are caused by transaction models, we need to improve our models. Every year we need to make some improvements over the previous year so that we can gradually improve our AR management. (Source: Requirements for Huawei's Business Management Strategy in the Current Period, EMT Meeting Minutes No. [2008] 035)

We must take a more scientific approach to payment collection. Moving future receivables forward will not be good for the company in the long run. (Source: Minutes of the Report on the 2011 HI Performance Review, EMT Meeting Minutes No. [2011] 011)

\subsubsection{Setting Up a Contract Support Office That Offers One- Stop-Shop Services to Support Contract Fulfillment}

Streamlining sales management, clarifying contract authorization, and establishing global contract centers

Can we have frontline sales people focus on key terms, like those that differ from standard contract terms or require extra negotiation, while following IBM's authorization and credit management framework? In my opinion, we can establish one or more contract guiding centers worldwide, like the bidding center in Pakistan. Contracts will no longer be prepared onsite; they will be airmailed to wherever they are needed. We currently have approximately 120 contract preparation centers, with employees working overtime to prepare contracts. We don't have many lawyers or credit managers so it's impossible to have both roles in each of these 120 countries. We certainly make mistakes because of this. I had an idea after listening to a presentation from two experts. With standardized management, everyone just needs to focus on their own part. For example, if I negotiate with a customer on extra contract terms, I need to review the negotiated terms and send them to the contract center after the negotiation. We only need to establish a few contract guiding centers worldwide. This way, more employees can be freed up and contract quality will be improved. In Canada, for example, contracts are signed by the research center chief, who has no experience dealing with sales contracts. This is because the contract preparation centers don't really need to be close to customers; we only need to engage closely with customers on key 
contract terms, often only two pages. (Ren Zhengfei: Speech at a Work Report by the IFS Project Team on October 16, 2007, ESC Meeting Minutes)

We must figure out a way for handling contract authorization and allocate experts and oversight personnel to establish a system for this. I think the first step is to streamline sales management. In the past, when something deviated from standards, I would say it was OK if something could not be streamlined. However, since we have started to work with IBM, our contracts need to be standardized. IBM may deliver us a standard template after working with us for one or two years. (Ren Zhengfei: Keeping Customer PO Information Transparent to Support Payment Collection, Revenue Recognition, and Project Budgeting and AccountingSpeech at a Work Report by the IFS Project Team on December 29, Huawei Executive Office Speech No. [2009] 002)

Establishing a comprehensive support platform to support and manage the end-to-end contract fulfillment process

Externally, CSO offers one-stop-shop services to customers; internally, it functions as a comprehensive support platform, responsible for managing contract handover, contract information entry and release, and order verification. It also provides the information and documents that are required for revenue recognition, issues invoices, monitors the end-to-end contract fulfillment process, and maintains contact with customers. (Ren Zhengfei: Keeping Customer PO Information Transparent to Support Payment Collection, Revenue Recognition, and Project Budgeting and Accounting - Speech at a Work Report by the IFS Project Team on December 29, Huawei Executive Office Speech No. [2009] 002)

$\mathrm{CSO}$ is responsible for managing basic contract information. All contract information is recorded by this department into the IT system. No other department is allowed to do this anymore. CSO is also responsible for contract management, goods preparation and shipment, delivery, revenue recognition, billing, and payment collection. Sales, delivery, and finance departments rely on CSO to complete billing and payment collection. (Ren Zhengfei: Keeping Customer PO Information Transparent to Support Payment Collection, Revenue Recognition, and Project Budgeting and Accounting-Speech at a Work Report by the IFS Project Team on December 29, Huawei Executive Office Speech No. [2009] 002)

\footnotetext{
${ }^{4}$ ESC stands for Executive Steering Committee, which oversees Huawei's transformation programs.
} 
CSO staff should be experienced people who have worked hard in hardship regions. We can give more opportunities to these people. People who have a good attitude and are willing to learn will have job opportunities at Huawei. Wherever things are tough, we will develop resource pools and managers. We must establish a platform, build a resource pool, and organize training sessions as soon as possible. Every piece of information must only have one owner in the company and must be shared throughout the processes. Before contract information is released, the sales department must ensure its completeness and accuracy. (Ren Zhengfei: Keeping Customer PO Information Transparent to Support Payment Collection, Revenue Recognition, and Project Budgeting and Accounting - Speech at a Work Report by the IFS Project Team on December 29, Huawei Executive Office Speech No. [2009] 002)

\subsection{Financial Management Throughout the IPD Process}

\subsubsection{The Essence of IPD: From Opportunity to Commercial Success}

A management system is a set of frameworks and decision-making rules. It does not change when individuals or operations change

Leading global companies attach great importance to $\mathrm{R} \& \mathrm{D}$, and their R\&D personnel are also responsible for technical sales, technical support, cost, and quality. They rely on R\&D to create opportunities and shape consumption. They quickly gather all profits within a short window of opportunity and then create even greater opportunities. This is why these companies develop faster than Huawei. This is why we went to the US to study management, to learn how a small company develops into a large one and evolves out of chaos. (Ren Zhengfei: What Can We Learn from the American People?, Improvement Issue No. 63, 1998)

If we don't have good management approaches during our large-scale operations, we may operate inefficiently and waste resources, and for that, we may pay the price of our lives. (Ren Zhengfei: Learning the Essence of IPD to Ensure Successful Transformation-Speech at the IPD Mobilization Meeting, Improvement Issue No. 90, 1999)

The IPD management system is our most important enabler of IPD. A management system is a set of frameworks and decision-making rules. It 
does not change when individuals or operations change. Here, the whole is greater than the sum of its parts. When a cross-department team acts as an integrated management and decision-making team, individuals and the organization play a much bigger role than they normally would. The IPD management system describes how different roles collaborate to ensure effective operations of the company. It is the internal gauge used to evaluate the value of IPD both inside and outside the company. (Source: Lew Kimmel, IPD Management System-Paving the Way for Huawei's Sustainable Development, Huawei People Issue No. 128, 2000)

The IPD management system describes how to manage relationships within a matrix organization. Every organization has its mission, role, and responsibilities, so the responsibility matrix is very clear and authority can be delegated to different teams as needed. These matrix organizations are often cross-department teams. Through flexible, effective communications, they focus on project goals and team management, and ensure that all relevant departments stay involved and collaborate. They also provide functional department inputs during each phase of product development. A team that runs effectively can help make the best decisions and take action based on facts. (Source: End-to-End Guide to Huawei's IPD Management System, 2016)

As long as we follow the IPD management system and process, our capabilities will improve and we will be able to develop high-quality products. We must change our past model that relied on individual heroes for success to a model where success is guaranteed through organizational effort. Any qualified Product Development Team (PDT) manager can develop successful products by leveraging their abilities and following the IPD management system and process. (Xu Zhijun: Being Clear About Your Role, Following the IPD Process, and Ensuring Timely and Highquality Delivery-Speech at the Annual Wrap-up and Commendation Meeting of Outstanding PDTs and TDTs, 2005)

Before 1999, Huawei occasionally launched good products by relying on individual or collective efforts. After we implemented IPD, however, we could systematically launch competitive products and solutions. (Guo Ping: 2011: Let's Start Anew-Speech at the Annual Meeting of Finance, Improvement Issue No. 376, 2011)

${ }^{5}$ TDT: Technology Development Team. 


\section{Managing product development as an investment and pursuing business success}

IPD looks at product development projects from a commercial perspective. One important consideration is finance. In other words, how should Finance work with IPD to measure the costs and benefits of a project? Before making an investment, an Integrated Portfolio Management Team (IPMT) must know how much money is available for investment. They need to know how many projects they can support given their current capabilities and how to assess a project from a commercial perspective. (Source: Involvement of All Departments Ensures IPD Success-Speech by IBM Consultant Arleta Chen at the IPD Mobilization Meeting, Improvement Issue No. 90, 1999)

Huawei has established an IPD process that focuses on customer needs. With this process, customer needs can be quickly and accurately incorporated into product release roadmaps. During this process, structured and standard parts are widely applied and technologies are fully shared. In the product development process, Huawei has established comprehensive advantages in speed, quality, and cost that have enabled the company to help customers gain a more competitive position. (Source: Huawei 2007 Annual Report)

According to Chinese-American scientist Li Kai, research is the process of converting money into knowledge, whereas development is a process of converting knowledge into money. Success represents premium customer experiences and highly competitive products. Therefore, technology is only a means to an end. It must align with customer needs, helping to deliver good user experiences and services and realize commercial value. (Ren Zhengfei: The Essence of IPD: From Opportunity to Commercial Success - Speech at an Awards Ceremony for IPD Whiz Kids and Outstanding XDTs, Huawei Executive Office Speech No. [2016] 084)

We must fully understand the core concepts surrounding IPD and follow processes in everything from reviewing opportunities to monetizing them. We must dare to take on difficult projects and achieve great success. We aim to establish a large system and a large platform. We must do some planning; otherwise, we will be unable to build our own Great Wall. China's Great Wall cannot change, but our Great Wall can, and we can rebuild parts of it at any time. If bricks in the groundwork of our own Great Wall are not replaced or optimized as time goes by, then our company will become rigid. (Ren Zhengfei: The Essence of IPD: From 
Opportunity to Commercial Success-Speech at an Awards Ceremony for IPD Whiz Kids and Outstanding XDTs, Huawei Executive Office Speech No. [2016] 084)

Shifting the focus of R\&D from technology to market-oriented innovation and becoming engineers with business acumen

We must think about everything we do with a commercial mindset, and look at problems from the perspective of the whole company, rather than the perspective of a department. When I visited the US, I asked people there what backgrounds or qualifications are required for IPD leaders? Their answer is: Don't see IPD as a task of R\&D; look at problems from a commercial perspective. This answer was quite impressive. You must not look at problems merely from your own department's perspective, but from a commercial perspective. (Source: Looking at Problems from a Commercial Perspective-Speech by Sun Yafang at an IPD Training Session, Improvement Issue No. 90, 1999)

Customers' business success is the ultimate measure of the value of any cutting-edge technology, product, or solution. When it comes to making decisions on product investment, we prioritize customer needs over technology. Our products and solutions can only remain competitive when we keep innovating in products and solutions based on our deep insights into customer needs. (Ren Zhengfei: My Thoughts on a 100-Year-Old Church That Survived the Wenchuan Earthquake-Speech at the Commendation Meeting of the Central Research \& Development Unit, Huawei Executive Office Speech No. [2008] 016)

Most employees in our R\&D team are engineers. They are eager to develop the best possible technology. They think that only by doing so can they prove their worth. In $R \& D$, if you do something right in a simple way, you may not get a high performance rating; but if you do it in a complicated way and make it look difficult, you may get a higher rating. This is not customer-centric. Customers want us to achieve the same results and deliver the same services in the simplest way. We need to recognize engineers with business acumen who can develop functions in a simple way. In doing so, we can encourage customer centricity in R\&D. I hope you can develop more business acumen rather than just being engineers. (Ren Zhengfei: Customer Centricity, Increased Platform Investments, and Open Collaboration for Shared Success-Speech at the 2010 PSST Managers' Meeting, Huawei Executive Office Speech No. [2010] 010)

\footnotetext{
${ }^{6}$ Sun Yafang: Chairwoman of the Board of Huawei from September 1999 to March 2018.
} 
We must move beyond the notion that "IPD is an R\&D process". In essence, it is a market-driven innovation process. As such, we must link product development to market analysis and segmentation, portfolio analysis, business strategy development, and planning. This means that we must rely on real, high-value customer needs to drive product development while fully considering needs such as manufacturability, installability, and serviceability. We need to complete business model designs and identify target users in the product development phase. (Guo Ping: Transform Continuously and Improve Field Operating Capabilities to Ensure the Company's Sustainable and Profitable Growth-Speech at Huawei Annual Management Conference 2013, Huawei Executive Office Speech No. [2014] 020)

\subsubsection{Key Control Points Throughout the IPD Process}

IPD can help Huawei establish a structured product development process and develop products according to a pre-set schedule. Cross-department teams made up of senior executives decide whether to continue with a product at specific decision checkpoints. This can help effectively manage company investment and product launches. (Source: IPD and Huawei's Dream, IBM-Huawei IPD Core Team, Improvement Issue No. 127, 2000)

Our R\&D team has over 70,000 people and is operating highly effectively. This is all because of our IPD process, a product development transformation initiated by Huawei and IBM in 1998. Since then, we have never stopped optimizing our R\&D processes, streamlining our organization, and improving R\&D capabilities. From ideation to product launch, we have never ceased improving our management systems, processes, tools, and capabilities. No matter how many people are involved - whether it's 70,000 or double that number - our management systems can still operate robustly and ensure that stable and quality products are made. This is attributed to our efforts in optimizing our management systems and R\&D processes over the years. (Source: Presenting a True Huawei, an Exclusive Interview with Xu Zhijun by Fortune, 2012)

With the IPD process, we no longer need to rely on "heroes" in product domains. Rather, we can develop products that meet customer needs and deliver an assured level of quality simply by relying on processes. ( $X u$ Zhijun: Streamlining and Integrating Processes for Operating Units, Realizing the "Five Ones" Target, and Achieving Consistency of Inventory Accounts and Goods-Speech at the Transformation and Management 
Improvement Session of the 2014 Huawei Market Conference, Huawei Executive Office Speech No. [2014] 018)

The key to the IPD management system is to manage the IPD process. The goal is to provide a management process and decision-making policy for company management so that they can monitor major business activities on an ongoing basis and make decisions to balance major businesses, achieve business goals, and take responsibility for performance and business results. (Source: End-to-End Guide to Huawei's IPD Management System, 2016)

The Finance Management Department of Products \& Solutions is a reliable business partner for product line presidents. They share responsibility for investment, operations, and internal controls management, supporting sustainable and profitable business growth. Finance uses specialized investment assessment methodologies to support the execution of corporate investment strategies and drive improvements in investment efficiency and effectiveness. They manage financial operations to align macro and micro activities, and execute financial and other relevant processes to effectively manage risks and achieve secure, robust operations. (Source: Notice on Positioning and Responsibilities of the Finance Management Department of Products \& Solutions, Group Finance Notice No. [2016] 027)

The Finance Management Department of Products \& Solutions takes the following responsibilities in terms of investment management:

1. Build a full series of investment management rules and an associated data reporting system.

2. Fully engage in the Develop Strategy to Execute (DSTE) and IPD processes, produce product investment analysis reports, and support business departments in making investment decisions.

3. Monitor and drive proper use of resources based on the company's business and financial strategies. Establish a mechanism for investment risk warning and escalation to drive efficient use of resources.

(Source: Notice on Positioning and Responsibilities of the Finance Management Department of Products \& Solutions, Group Finance Notice No. [2016] 027)

In an IPMT, responsibilities of finance members are as follows:

1. Give financial advice and identify opportunities from a financial perspective to ensure that the product line hits its revenue and expense 
targets and executes its business strategies. Monitor and track product line and product costs to ensure that they are within expectations.

2. Provide financial guidance and expert advice when reviewing product investment portfolios and offering guidance to individual Business Management Teams (BMTs) and Super Product Development Teams (SPDTs). Review and sign off on financial information in business plans to ensure that the information is complete and accurate.

3. Review the consistency between suggestions on product development investment and investment baselines and ask relevant teams to explain when there are inconsistencies.

4. Ensure financial data of product lines and budgeting and accounting data of product releases are provided in a timely and accurate manner to support product line operations and fine-grained management.

5. Monitor and manage promised financial capability improvement activities and ensure that product lines have skilled financial personnel in place to provide the most competitive financial support for projects and investment portfolios. Maintain a list of financial resources (including people, expenses, and assets) and allocate necessary resources to PDTs at a certain DCP.

6. Hold regular meetings to guide BMT/SPDT finance members in fulfilling their responsibilities and providing feedback when it comes to a common business issue or an issue specific to a BMT/SPDT.

7. Implement IPMT resolutions and requirements for finance, monitor the performance of BMT/SPDT finance members, and provide inputs to their performance appraisals.

(Source: End-to-End Guide to Huawei's IPD Management System, 2016)

\subsubsection{Industry Business Plans and Product Investment Portfolio Management}

A company's ultimate goal is to earn profits. Product investment decisions are made based on product financial assessments. In the past, we decided whether to invest in a product's development after we roughly estimated its potential profit based on the estimated cost and sales price. However, questions that are commonly considered in a standard financial analysis were ignored in this process. In the IPD process, the product development team includes financial personnel who perform project cost and ben- 
efit analyses from a financial perspective and produce a comprehensive financial analysis report, informing investment decisions. We now have begun to make product investment decisions from a commercial perspective, marking a dramatic change in our approach. (Source: Summary of the First Pilot of IPD in a PDT (II), Improvement Issue No. 161, 2001)

We must enhance investment portfolio management, including investment allocation and the pace of investment. We need to pragmatically assess market size, profit models, and returns on investment. Based on these objective assessments, we can then determine the amount and pace of our investment. (Source: Resolution on the Positioning and Business Development Strategy for the IT Product Line, SDC Resolution No. [2012] 006)

Product and technology investment portfolios must be properly prioritized. Strategic plans (SPs) and business plans (BPs) for investment strategies and ROI must be closely linked. We need to specify the strategy for product and technology investment portfolios. We must have a clear strategic positioning and define investment priorities for every industry. And the strategies for product and technology investment portfolios of an industry must be prepared with SPDT as the basic unit. We need to set our three-year goals and the goals of year 2015 for returns from R\&D investment, operating results, and product or technology competitiveness. Business units must invest enough to future-proof their core competencies. They should not pursue short-term performance at the expense of long-term investment. (Source: Principles for R\&D Investment Management and Budgeting Rules in 2015, SDC Business Directive No. [2014] 005)

IPMTs must make investment decisions based on pre-defined industry SPs and think with a commercial mindset. They need to manage investment in a closed-loop manner by physical industry, not organization. This is because organizations may change, but physical industries will not. (Source: Minutes of the Report to Xu Zhijun on the Project Charter of the Product Investment Portfolio Management Mechanism, 2014)

According to SP and BP rules, Finance must formulate operations management rules based on a business department's long-term strategic pursuits and short-term business goals, and use these rules to guide business departments to self-balance their long-term strategies and short-term operations. Business departments must not cut long-term strategic investment due to short-term performance pressures, or tolerate long-term losses to preserve strategic investment. Our ideal operations management 
should be: Having rice in our bowls, paddies in our fields, and rice in our warehouses. (Meng Wanzhou: Using Budgets to Drive Resource Allocation and Aligning Resource Allocation with Strategies, Huawei Executive Office Speech No. [2014] 001)

Industries vary greatly, so R\&D investment must be managed on an industry-by-industry basis. BUs must determine how to allocate their resources based on the revenue from target customers of a product. A BU's revenue refers to the total revenue from all of its global customers. (Source: Principles for ReD Investment Management and Budgeting Rules in 2015, SDC Business Directive No. [2014] 005)

We can allocate $R \& D$ resources using three approaches: ratios, amounts, and amounts plus ratios. Strategy, ROI, and product lifecycles are considered during this process. For products in the investment or decline periods, investment is managed based on amounts. For products in the growth or maturity periods, investment is managed based on pre-set ratios. Strategic investment made by the 2012 Laboratories is managed based on amounts and constrained by the R\&D expense ratio set by the company. (Source: Principles for RUDD Investment Management and Budgeting Rules in 2015, SDC Business Directive No. [2014] 005)

\subsubsection{Integrating IPD and Other Business Processes}

For years, Huawei has been learning and introducing management systems and processes, such as IPD, ISC, IFS, and CRM, from Western companies. When we introduced these processes, we gave up some parts of them due to our lack of knowledge and capabilities, and their suitability at that time. Currently, the problems we are facing in management, such as breakpoints, low efficiency, and process congestion, are to a large extent attributable to our failure to make full use of these management systems in the first place. During our management transformation, the biggest challenge is integration across functional departments. We need to systematically manage the interconnections and relationships between different transformation programs to create the end-to-end backbone of our management system. (Source: Minutes of the Report on Initial Findings from the Review of Corporate Transformation Programs and Suggestions on ESC/ PO Restructuring, EMT Meeting Minutes No. [2014] 005)

${ }^{7}$ PO: Project Office, supporting ESC operations. 
Huawei's approach to management transformation can be compared to clouds, rainwater, and channels. (The cloud is Huawei's management philosophy. The rainwater is our business activities. And channels are the processes and theories that summarize the best practices of Western companies.) We must have the right channels in place to gather our rainwater together and generate electricity. We need to integrate our IFS, IPD, ISC, and LTC processes to form the right channels. Huawei's management philosophy is like a cloud, which is valuable only when it turns into rainwater. And the rainwater needs to be channeled properly. Without the right channels to guide the rainwater, it will flow anywhere, and its energy will dissipate. (Ren Zhengfei: Rigorous, Well-ordered, and Simple Management Is Crucial for Huawei to Scale New Heights, Huawei Executive Office Speech No. [2014] 028)

Last year, we proposed a new concept: object-oriented process integration. This means we must check whether our processes are truly streamlined and integrated for representative offices, regional offices, BUs, BGs, and other operating entities. We also need to check whether our processes can truly support our operating units' efforts to continuously improve operating efficiency, customer satisfaction, and profitability. The first transformation process we implemented at Huawei was IPD. The score of this process in the capability maturity assessment (CMA) has been around 3.2 points over the years. Why can't we hit our initial 3.5 point goal? Because we can only achieve 3.5 points when all relevant processes are integrated. That can't be achieved with the IPD process alone. Only when the IPD process is integrated with other processes in a way that focuses on objects can it achieve a score of 3.5 points in the CMA. To do this successfully, we must improve our overall efficiency. The same holds true for other processes. Every other process, including the LTC and the Issue to Resolution (ITR), must be integrated with other processes in a way that focuses on objects, and must support our operating units' efforts to continuously improve operating efficiency, customer satisfaction, and profitability. Only in this way can they achieve a 3.5 point CMA score. ( $X u$ Zhijun: Streamlining and Integrating Processes for Operating Units, Realizing the "Five Ones" Target, and Achieving Consistency of Inventory Accounts and Goods-Speech at the Transformation and Management Improvement Session of the 2014 Huawei Market Conference, Huawei Executive Office Speech No. [2014] 018)

After many years of transformation, our vertical process design and development is essentially completed, except a few processes that still need 
time for deployment and optimization. Now we need to integrate processes to improve operating units' operating efficiency, customer satisfaction, and profitability. At this stage, representative offices and regional offices need to take more responsibility in process transformation and even become process deployment owners, because they are primarily the ones who will implement object-oriented process integration. (Xu Zhijun: Streamlining and Integrating Processes for Operating Units, Realizing the "Five Ones" Target, and Achieving Consistency of Inventory Accounts and Goods-Speech at the Transformation and Management Improvement Session of the 2014 Huawei Market Conference, Huawei Executive Office Speech No. [2014] 018)

\subsection{Financial Management Throughout the PTP Process}

\subsubsection{KCPs Throughout the PTP Process}

Reviewing the procurement process architecture, setting KCPs for payment security, and providing effective guidance to procurement

Huawei has seven procurement processes that are classified based on factors like business codability, IT system maturity, and procurement department involvement. This makes it difficult to modify and upgrade these processes. These processes were developed based on our business operation models and cannot support new business models like monthly payments for logistics service POs. In addition, since process classification criteria are not unified, processes become optional and users can bypass controls by choosing processes they like. Sometimes they even end up increasing operating costs by choosing a complex process for a business activity that is supposed to follow a simple process.

The PTP project team has come up with an approach to improving the existing seven procurement processes and will work with the ISC Business Process Executive (BPE) and the procurement department to implement it. Our current focus is on defining each of the seven processes' business scope and rules for use and setting KCPs for payment security. The purpose of these two actions is to allow our existing processes to provide a clearer guide for business operations. In the future, the seven processes will be gradually integrated into one common, modularized process as codes are applied to procurement activities and the ERP system is deployed for procurement. (Source: Optimizing the Procure-to-Pay Process to Ensure 
Secure, Accurate, and Timely Payment, IFS-PTP Project Team, Improvement Issue No. 308, 2008)

Huawei has six accounts payable (AP) payment processes that are classified based on different standards, with complicated categories. The initial purpose of classifying them like this was to establish payment processes that are aligned with each procurement process. This makes payments inefficient and also makes it inconvenient to provide business support and centralize payment operations. For PO-based procurement, IBM has a common payment process. For procurement without a PO, IBM has a payment process called Invoice Only Invoice (IOI). Its payment process is divided into several activities including invoice receiving and processing, invoice matching, duplicate payment checking, and payment. The process architecture is very clear and can provide a useful guide for business operations. (Source: Optimizing the Procure-to-Pay Process to Ensure Secure, Accurate, and Timely Payment, IFS-PTP Project Team, Improvement Issue No. 308, 2008)

Establishing and optimizing the supplier invoice processing process and making invoice processing more efficient

Huawei has no clear guide for handling supplier-issued invoices. We have no way of ensuring suppliers issue correct invoices the first time. Our processes for collecting, transmitting, approving, entering, and querying invoice information are also not well-established and we have no process for handling problematic invoices. As a result, invoice processing is inefficient. The PTP project team plans to develop a guide for supplier invoice issuance and a process for handling problematic invoices. The team will also optimize our existing processes for collecting, transmitting, approving, entering, and querying invoice information to make invoice processing more efficient. (Source: Optimizing the Procure-to-Pay Process to Ensure Secure, Accurate, and Timely Payment, IFS-PTP Project Team, Improvement Issue No. 308, 2008)

Adding duplicate payment checking into the AP payment process and enabling the function in ERP

In Huawei's existing AP payment process, duplicate payment is checked by people without any clear process in place. The work is not done systematically or routinely. IBM's mechanism for duplicate payment checking includes both pre-payment and after-payment checks. A report is then sent to the AP and other relevant departments on a daily basis to ensure that only one payment is made to an external supplier for the same transaction. With this mechanism, duplicate payment can be prevented. Even if a prob- 
lem is detected, it can be fixed immediately, reducing the company's financial losses. (Source: Optimizing the Procure-to-Pay Process to Ensure Secure, Accurate, and Timely Payment, IFS-PTP Project Team, Improvement Issue No. 308, 2008)

\section{Optimizing the governance mechanism for the PTP process}

The PTP project team plans to work with the Business Controls and Internal Audit (BC\&IA) project team to build an SOD matrix and an assessment mechanism and further improve the risk acceptance mechanism. The team will also clearly define which procurement activities bypass the procurement department and establish a mechanism for identifying, recording, reporting, and assessing bypass activities. They will also set KCPs throughout the PTP process and perform process compliance testing to improve the PTP process's governance mechanism. (Source: Optimizing the Procure-to-Pay Process to Ensure Secure, Accurate, and Timely Payment, IFS-PTP Project Team, Improvement Issue No. 308, 2008)

Cleaning up supplier information, optimizing the mechanism for managing and maintaining supplier information, and ensuring that payment for one transaction is made securely and only once

Currently, Finance maintains our suppliers' bank information and Procurement manages all other supplier information. Poor coordination between these departments results in low efficiency and duplicate work. As supplier information is not updated or maintained as quickly as it should, our system is full of duplicate suppliers and suppliers who have not worked with us for a long time. This can cause payment delays and errors. By using IBM as a benchmark, our Procurement Operations Support Department has established a dedicated team to solve this problem. This team has cleaned up supplier information and will further improve our supplier information management policy based on the PTP project team's findings. The team will decide who will be responsible for entering and maintaining supplier information to ensure that the information is valid, complete, accurate, and unique and that payment for one transaction is made securely and only once. (Source: Optimizing the Procure-to-Pay Process to Ensure Secure, Accurate, and Timely Payment, IFS-PTP Project Team, Improvement Issue No. 308, 2008)

Pushing for the standardization of internal procurement requests, simplifying request approvals, and improving efficiency

The procurement team needs to ask requesting departments to streamline their request approval processes and standardize their procurement requests. Currently, the main pain points in procurement processes are 
bloated internal request approval processes and unclear request descriptions. Requesting departments need to clearly describe their requests and make continuous improvement. The procurement team should not assume responsibility for the quality of requests themselves. (Ren Zhengfei: Minutes from a Procurement Work Report by Yao Fubai, Huawei Executive Office Speech No. [2017] 048)

Adhering to the principle of transparent procurement, and strengthening the management of supplier honesty and integrity

Suppliers that violate Huawei's BCGs are to be penalized according to the Honesty and Integrity Agreement. We need to prevent suppliers from doing things like bribing employees, including indirectly through family members. Procurement managers have to report all conflicts of interest. This isn't to say that procurement isn't possible when there are conflicts of interest. But these conflicts need to be reported for transparency. (Ren Zhengfei: Minutes from a Procurement Work Report by Yao Fubai, Huawei Executive Office Speech No. [2017] 048)

\subsubsection{Integrating Procurement and Financial Processes}

Implementing the "Four Unifications" and benchmarking Huawei's procurement accounting against international practices

In September 1998, we hired KPMG to help us launch the "Four Unifications" project in Finance, which involved unifying policies, processes, codes, and tables. In the first half of 1999, KPMG began to help us design and improve our accounting system based on leading financial practices and proposed new processes and policies. As procurement was a relatively standard activity and most of our suppliers were large global companies, we applied these practices to procurement accounting first. With the joint effort of the KPMG consultants, the project team, and all involved employees, our "Four Unifications" solutions were applied to procurement accounting. We have seen tangible results from this. This has made us more determined to widely roll out the "Four Unifications" and has further encouraged us to benchmark our procurement accounting against international standards. (Source: Implementing "Four Unifications" to Reach International Standards in Procurement Accounting, Improvement Issue No. 126, 2000)

The procurement accounting section has developed or improved our regulations on procurement payment and made improvements to our pro- 
cesses, oversight, and tables. In October 1999, we successfully switched to the Chart of Accounts (COA). This has greatly improved the timeliness and accuracy of our accounting, as well as our fund security and work efficiency. (Source: Implementing "Four Unifications" to Reach International Standards in Procurement Accounting, Improvement Issue No. 126, 2000)

Optimizing the PTP process from a financial perspective and moving towards project-driven procurement

The reason procurement costs cannot be accounted for at a project level is that procurement is not project-driven. If procurement was already project-driven, wouldn't project-level procurement cost accounting already be implemented? We must now emphasize that procurement must be project-driven. This is consistent with our policy that says the front line must be allowed to ask for the resources they require. Our project management needs to take a longer-term view. We can develop our project procurement plans a few months in advance so that they can drive procurement. The centralized approach we adopted previously meant we didn't have a clear view of things. We must change this approach; otherwise, we will never achieve scientific, fine-grained project management. (Ren Zhengfei: Speech at a Work Report by the IFS-PTP Project Team, 2010)

Whoever makes a purchase must make the associated payment and bear the corresponding costs. All procurement costs must be charged to projects. Procurement personnel will be held accountable where this is not achieved. We don't need to seek globally unified cost baselines. Every country office, regional office, and project can have its own baselines. They can use these baselines to push themselves to do better. (Ren Zhengfei: Speech at a Work Report by the IFS-PTP Project Team, 2010)

Remaining user-centric, supporting frontline business, and making general procurement easier

General procurement involves a lot of small details, from stationery purchase to car or house rental. This is a part of our everyday work. After years of procurement transformation and the deployment of our AP process, we finally have a relatively unified and simplified AP process for general procurement. However, our business operations are still manual. Only part of HQ procurement is supported by IT systems and these systems are largely decentralized and not well integrated, making general procurement personnel in field offices very frustrated. How can we address these difficulties facing our field offices and make general procurement easier? 
The General Procurement Department, the IFS-PTP Project Team, the Internal Service Management Department, the Accounting Management Department, and the Quality, Business Process \& IT Management Department have established a joint work group to improve relevant processes and IT systems. After nearly a full year, starting in the second half of 2008, we have launched a web-based system called eGo globally to support general procurement. eGo is designed to be user-centric. Its purpose is to make our processes faster, internal controls more effective, and operations easier.

There is only one process and one point of entry and the entire process is visible. All general procurement will be done on this platform. Procurement requesters can find the items or services they want to purchase in the system catalog and both payments to suppliers and reimbursements to employees who make advance payments on behalf of the company will be done in this system. This will make procurement requests and expense analysis and management easier.

With this system, approvals are streamlined and real-time budgets are provided for reference. Only one approval is required after a procurement request is submitted. No further approval is required to make a payment. Approvers can approve requests anywhere and at any time. They can also delegate approval to others in the system. More importantly, managers can see how much of their department's budget has been used during approval and get detailed reports of purchased items. Thanks to this system, managers can have more information available so they can make informed approvals, reduce internal control risks, and trace issues when they occur.

In the eGo system, supplier qualification information is shown in catalogs. The system translates the qualification information into a catalog of items and services that can be purchased. This information includes supplier names, item and service descriptions, and prices. All the information is shown to users in the form of a catalog, like on an online shopping platform. Employees can find a wide variety of items and services to be purchased and complete their purchases themselves. Procurement qualification personnel can set up different catalogs to support different procurement models. This way, Huawei can make full use of qualified suppliers and procurement authorization can also be managed using the system.

In this system, documents can be automatically matched during accounting. No matter what type of business it is, the eGo system can 
generate PRs, POs, and acceptance information in a unified format. That $\mathrm{PO}$ and acceptance information can then be automatically imported into ERP. When Finance makes payments, they only need to input invoice information and the system will automatically match the invoice with the corresponding procurement, boosting efficiency and reducing manual errors. According to our estimations, Huawei may lead the industry in terms of annual invoice processing capacity once eGo is fully rolled out.

In addition, different requirements for internal controls are fully embedded and codified into this system, ensuring process compliance. (Source: We Can Make General Procurement Easier, IFS-PTP Project Team, Improvement Issue No. 343, 2009)

Simplifying the procurement process for low-value consumables and changing the way we offset the payment of low-value procurement

We must buy low-value consumables at supermarkets since most of these items are available there. We only need to qualify supermarkets and not the commodities sold at the supermarkets. We can use the rules that supermarkets already use to manage our procurement of low-value consumables. Low-value items can be purchased by employees directly. They can then get reimbursed by submitting an expense claim in the Self-service Expense (SSE) system. They don't need to follow the formal procurement process for these items. (Ren Zhengfei: Speech at a Work Report by the IFSPTP Project Team, 2010).

We must do everything we can to streamline our processes. Complicated processes only make oversight more difficult and more costly. (Ren Zhengfei: Speech at a Work Report by the IFS-PTP Project Team, 2010).

\subsubsection{Automation and Payment Security of the PTP Process}

When implementing the PTP project, Huawei needs to focus on big issues. For items used in production lines, we must do exactly as our consultants say. For low-value office supplies, however, consultants can set less strict requirements. In the past, our offices had to use a very rigid system to procure the smaller items they needed. For example, suppliers had to be qualified for even just a pencil or a piece of paper. In some representative offices, a contract may be worth US $\$ 500$ million; in some others, a contract may be worth only US\$2 million. We used to be very rigid in this regard. That's why we had 300 people qualifying pencil and paper suppli- 
ers worldwide. Our final solution was to buy these items at big-name supermarkets. That way, we only need to qualify the supermarkets, rather than the items. You must use credit cards, not cash, when buying these items at supermarkets. What you have purchased must then be put in the system for everyone to see before you get them reimbursed online. Supermarket prices are fair, which helps us prevent internal problems in terms of inaccuracies and prices. With fair prices, we can set limits for the procurement of office necessities based on our pre-set budgets. Departments can then adjust the quantity of items they require based on the limits. In this regard, Huawei and IBM are a little different. In the PTP project, we need to focus on high-value, major items. For these items, we must do exactly as our IBM consultants say. For low-value items, we can consider their transformation in the future. (Ren Zhengfei: Speech at a Work Report by the IFS Project Team on December 14, 2007, ESC Meeting Minutes)

We must gradually implement AI-aided, standardized procurement of auxiliary engineering materials and allow each country office to make its own choices. Standard templates must also be used for engineering procurement. We need to build cost models for typical sites, but these models do not need to be overly detailed. We must be quality-centric, rather than price-centric in all procurement categories. We must work toward higher quality and higher quality will require higher costs. We need to drive higher quality among suppliers and offer them premium prices for higher quality items. (Ren Zhengfei: Minutes from a Procurement Work Report by Yao Fubai, Huawei Executive Office Speech No. [2017] 048)

The department responsible for procuring auxiliary engineering materials can look to the successful use of AI in general procurement to gradually standardize operations. We must ensure normalization by category, and establish item codes and a shortlist of qualified suppliers. There must be globally unified guidelines and each country office must be given the freedom to make their own choices. Quality is the foundation of big data analytics. (Ren Zhengfei: Minutes from a Procurement Work Report by Yao Fuhai, Huawei Executive Office Speech No. [2017] 048)

Intelligence and automation are where we are all heading, but during this process, we should not overly simplify or marginalize human work. 
1. Intelligence and automation are where we are heading. They will make payments more secure, but don't think they will replace people. That's a common misconception about how these tools work. The work done by machines is not always 100\% accurate and machines are unable to flexibly respond to many changes. It's true that machines can do standardized work efficiently, but that doesn't mean that they don't make any errors. For some positions and industries, we just can't afford to have machines making errors. Today's flight technology relies on machines for many tasks, especially after planes reach a certain altitude and begin to cruise. Despite that, machines will never replace captains since they can never truly play the role of a captain. Would you dare to get on a plane that didn't have a captain?

2. Intelligence can help our payment personnel rapidly identify possible errors in massive amounts of data. Automation can help them find the right documents from huge amounts of files. But the "Go" button still needs to be pressed by people. Intelligence and automation can help payment personnel improve their work quality, rather than marginalizing and simplifying their work.

3. Automatic scanning can replace manual item-by-item checking. Payment personnel are supposed to focus their time and effort on key issues and maximize the value of their experiences, skills, comprehensive judgment, and analysis. I hope that automation and intelligence can encourage our payment personnel to proactively reflect on their operational skills and judgment to prevent future business problems.

(Ren Zhengfei: Speech at a Meeting with Payment Staff, Huawei Executive Office Speech No. [2017] 042)

Security, not innovation, is the most important consideration when we choose payment platforms and methods. We prefer using mature, traditional methods and channels rather than follow trends. We cannot innovate for the sake of innovation or become too focused on expanding or using new payment methods and channels. We must use secure, traditional payment methods, but we allow customers to use different payment methods. We must strictly assess, carefully analyze, and fully validate payment methods and channels before using them. Only when all its risks 
have been identified and eliminated can we try out a new payment method. We can formally introduce a payment platform only after it is proved to be secure and reliable through a long-time trial. (Ren Zhengfei: Speech at a Meeting with Payment Staff, Huawei Executive Office Speech No. [2017] 042)

Open Access This chapter is licensed under the terms of the Creative Commons Attribution-NonCommercial-NoDerivatives 4.0 International License (http:// creativecommons.org/licenses/by-nc-nd/4.0/), which permits any noncommercial use, sharing, distribution and reproduction in any medium or format, as long as you give appropriate credit to the original author(s) and the source, provide a link to the Creative Commons licence and indicate if you modified the licensed material. You do not have permission under this license to share adapted material derived from this chapter or parts of it.

The images or other third party material in this chapter are included in the chapter's Creative Commons licence, unless indicated otherwise in a credit line to the material. If material is not included in the chapter's Creative Commons licence and your intended use is not permitted by statutory regulation or exceeds the permitted use, you will need to obtain permission directly from the copyright holder. 